\title{
La terapia cognitiva y la imipramina, solas o combinadas, fueron efectivas en el tratamiento de los desordenes de pánico
}

Cognitive-Behavioral Therapy, Imipramine, or Their Combination for Panic Disorder. Barlow DH, Shear MK, Gorman JL, et al.JAMA 2000;283:2529-2536.

\section{Objetivo}

Evaluar la efectividad del tratamiento farmacológico (imipramina) y de la psicoterapia (terapia cognitiva) tanto solas como combinadas, y contra placebo, en los desordenes de pánico.

\section{Diseño}

Ensayo clínico randomizado doble ciego con un seguimiento promedio de 15 meses.

\section{Lugar}

Estudio multicentrico realizado en 4 clínicas de E.E.U.U. que trabajan con trastornos de ansiedad, entre Mayo de 1991 y Abril de 1999.

\section{Pacientes}

Se incluyeron 312 pacientes con desordenes de pánico. La población era predominantemente de sexo femenino $(62,5 \%)$, de raza blanca $(90,8 \%)$, y con edades entre 25,4 y 46,8 años. Fueron excluidos pacientes con diagnóstico de psicosis, trastorno bipolar, suicidas potenciales, abusadores de drogas y aquellos que presentaran alguna comorbilidad que contraindicara el tratamiento.

\section{Intervención}

Los pacientes se randomizaron a 5 grupos. Grupo $1(n=83)$ recibieron imipramina a dosis de hasta $300 \mathrm{mg}$-/dia. Grupo $2(\mathrm{n}=77)$ recibieron solo asistencia con abordaje de terapia cognitiva. Grupo 3 ( $n=24)$ recibieron placebo. Grupo $4(n=65)$ recibieron combinación de terapia cognitiva e imipramina. Grupo $5(n=63)$ recibieron la combinación de terapia cognitiva y placebo. A todos los pacientes se les ofreció tratamiento semanal por 3 meses (fase aguda), los que respondieron fueron tratados por 6 meses más (fase de mantenimiento) y fueron seguidos por otros 6 meses luego de finalizar el tratamiento.

\section{Medición de resultados principales}

Respuesta al tratamiento de desorden de pánico, evaluada por los médicos tratantes a través de 2 escalas. Escala de Severidad de Desorden de Panico (PDSS) ${ }^{1}$ y una escala de impresión clínica, de compromiso o de mejoría: la Escala de Impresión Clínica Global (CGI). Ambas escalas están validadas por ensayos clínicos randomizados y controlados.

\section{Resultados principales}

La edad promedio de los pacientes fue 36,1 años $+/-10,7$. El cuadro siguiente expresa los porcentajes de respuestas positivas al tratamiento en cada grupo, para cada fase del estudio y por ambas escalas de medición, analizadas por intención de tratar.

\begin{tabular}{l|c|c|c|c|c}
\hline & $\begin{array}{c}\text { Grupo 1 } \\
\text { Imipramina } \\
\text { resp. \% }\end{array}$ & $\begin{array}{c}\text { Grupo 2 } \\
\text { Psicoterap. } \\
\text { resp. \% }\end{array}$ & $\begin{array}{c}\text { Grupo 3 } \\
\text { Placebo } \\
\text { resp. \% }\end{array}$ & $\begin{array}{c}\text { Grupo 4 } \\
\text { Imip+Psicot. } \\
\text { resp. \% }\end{array}$ & $\begin{array}{c}\text { Grupo 5 } \\
\text { Psico+Place } \\
\text { resp. \% }\end{array}$ \\
\hline $\begin{array}{l}\text { Fase xPDSS } \\
\text { Aquda xCGI }\end{array}$ & 45,8 & 48,7 & 21,7 & 60,3 & 57,1 \\
\hline & 48,2 & 53,9 & 37,5 & 64,1 & 61,9 \\
\hline $\begin{array}{l}\text { Fase xPDSS } \\
\text { Mant. xCGI }\end{array}$ & 37,8 & 39,5 & 13,0 & 57,1 & 46,8 \\
\hline & 37,8 & 42,1 & 13,0 & 56,3 & 50,0 \\
\hline $\begin{array}{l}\text { Segui. xPDSS } \\
\text { Post. xCGI }\end{array}$ & 19,7 & 32,4 & 9,1 & 25,0 & 41,0 \\
\hline & 19,7 & 31,9 & 13,0 & 26,3 & 41,0 \\
\hline
\end{tabular}

\section{Conclusiones}

La combinación de imipramina más psicoterapia cognitiva fue el tratamiento más efectivo para los desordenes de pánico tanto en la fase aguda como en la de mantenimiento, usando dosis de $200 \mathrm{mg}$./día promedio. En el seguimiento posterior el grupo de psicoterapia más placebo fue el que tuvo mejor respuesta. Se concluye que el tratamiento con imipramina logra la remisión de muchos de los síntomas pero el tratamiento con psicoterapia es de mayor durabilidad y mejor tolerancia.

Fuente de financiamiento: Pfizer laboratorio, National Institute of Mental Health, Psycological Corporation, Eli Lilly lab., BMS Lab.y otros.

\section{COMENTARIO}

En 1980 se reconoce oficialmente al desorden de pánico como un síndrome con un criterio diagnóstico preciso. Previamente se lo denominaba "corazón irritable", "corazón de soldado" y "síndrome de hiperventilacion" aludiendo a los síntomas que los pacientes experimentaban. La etiología del desorden de pánico resulta desconocida, pero investigaciones clínicas sugieren una disfunción en el sistema de alarma cerebral, posiblemente involucrando algunos neurotrasmisores. Como parte de la historia clínica del desorden de pánico, un tercio a una mitad de los pacientes suelen desarrollar agorafobia, que comúnmente incluye miedo de estar en lugares públicos, sobre todo en situaciones donde el escape puede ser difícil y la ayuda está fuera de alcance. No es raro que estos pacientes hagan "entrar en pánico" a sus médicos tratantes, desprevenidos de este síndrome psicopatológico con tanto impacto somático. El desorden de pánico se presenta con: taquicardia sinusal, precordalgia, transpiración, disnea, mareos, cefaleas, temor de morirse o perder el control entre otros síntomas. El examen físico y la historia clínica son normales; el electrocardiograma solo puede mostrar una leve taquicardia. En este estudio se utilizó la imipramina como droga de elección, no obstante los autores aclaran que no existían en ese momento en el mercado los inhibidores de la recaptacion de serotonina (IRS). Este grupo se ha convertido en la elección del tratamiento antidepresivo farmacológico puesto que tiene mejor tolerancia, menor numero de contraindicaciones y mayor rapidez y efectividad. 23

Dentro de los tratamientos farmacológicos las benzodiazepinas son una eficaz herramienta para el tratamiento global del espectro sintomático pánico-agarofobico, que incluye la ansiedad anticipatoria y el grado de fobia presente. Y dentro de las benzodiazepinas el clonazepan por su fármacocinética permite una cómoda dosificación con menos fenómenos de rebote de ansiedad interdosis y menos posibilidad de producir síntomas de abstinencia a la discontinuación, debido a su larga vida media. ${ }^{4}$ La terapia cognitiva pone a prueba las falsas creencias y las conceptualizaciones distorsionadas, cuestiona los pensamientos e imágenes automáticas y los hace concientes. Se trata de la aplicación del modelo cognitivo a un desorden psicológico particular. Esta línea psicoterapeutica demostró ser exitosa para la terapia del desorden de pánico. ${ }^{5}$ El uso de imipramina hoy en día queda relegado al tratamiento de desorden de pánico cuando acompaña a otros cuadros suceptibles de tratarse con esta droga.

Dra. Analía Gimeno Médica psiquiatra psicoanalista. Instituto Municipal de rehabilitación de Vicente López. Dr. Marcelo Ikonikoff Referencias Médico de la Unidad de Medicina Familiar y Preventiva. Hospital Italiano de Buenos Aires.

1. Multicenter colaborative panic disorder severity scale.Schear M.K., Brown TA, Barlow DH, et al. Amj psy 1997 nov-154 (11):1571-5.

2. The effect of Citalopram in panic disorder.Br] Psychiatry.1997;170:549-553.

3. Doubled-blind pilot trial of desipramine versus fluoxetine in panic patients. Anxiety. 1994-1995;1:287-290.

4. Clonazepan vs Alprazolam en el Trastorno del panico con agarofobia.Rev.Neuropsicof clin 1999.vol. IV num.23.6-13.

5. Nuevas ciencias de la conducta.Kerman B.,Lutz F.,Ugarte M.,Ed.Uflo. 